\title{
Article \\ A Novel Target (Oxidation Resistant 2) in Arabidopsis thaliana to Reduce Clubroot Disease Symptoms via the Salicylic Acid Pathway without Growth Penalties
}

\author{
Regina Mencia ${ }^{1}$, Elina Welchen ${ }^{1} \mathbb{D}$, Susann Auer ${ }^{2}$ and Jutta Ludwig-Müller 2,*(D) \\ 1 Instituto de Agrobiotecnología del Litoral, Consejo Nacional de Investigaciones Científicas y Técnicas, \\ Cátedra de Biología Celular y Molecular, Facultad de Bioquímica y Ciencias Biológicas, Universidad Nacional \\ del Litoral, Santa Fe 3000, Argentina; rmencia@santafe-conicet.gov.ar (R.M.); ewelchen@fbcb.unl.edu.ar (E.W.) \\ 2 Faculty of Biology, Technische Universität Dresden, 01062 Dresden, Germany; Susann.Auer@tu-dresden.de \\ * Correspondence: Jutta.Ludwig-Mueller@tu-dresden.de
}

check for

updates

Citation: Mencia, R.; Welchen, E.;

Auer, S.; Ludwig-Müller, J. A Novel Target (Oxidation Resistant 2) in Arabidopsis thaliana to Reduce Clubroot Disease Symptoms via the Salicylic Acid Pathway without Growth Penalties. Horticulturae 2022, 8,9. https://doi.org/10.3390/ horticulturae 8010009

Academic Editor: Edel Pérez-López

Received: 23 November 2021

Accepted: 16 December 2021

Published: 22 December 2021

Publisher's Note: MDPI stays neutral with regard to jurisdictional claims in published maps and institutional affiliations.

Copyright: (C) 2021 by the authors. Licensee MDPI, Basel, Switzerland. This article is an open access article distributed under the terms and conditions of the Creative Commons Attribution (CC BY) license (https:// creativecommons.org/licenses/by/ $4.0 /)$.

\begin{abstract}
The clubroot disease (Plasmodiophora brassicae) is one of the most damaging diseases worldwide among brassica crops. Its control often relies on resistant cultivars, since the manipulation of the disease hormones, such as salicylic acid (SA) alters plant growth negatively. Alternatively, the SA pathway can be increased by the addition of beneficial microorganisms for biocontrol. However, this potential has not been exhaustively used. In this study, a recently characterized protein Oxidation Resistant 2 (OXR2) from Arabidopsis thaliana is shown to increase the constitutive pathway of SA defense without decreasing plant growth. Plants overexpressing AtOXR2 (OXR2-OE) show strongly reduced clubroot symptoms with improved plant growth performance, in comparison to wild type plants during the course of infection. Consequently, oxr 2 mutants are more susceptible to clubroot disease. P. brassicae itself was reduced in these galls as determined by quantitative real-time PCR. Furthermore, we provide evidence for the transcriptional downregulation of the gene encoding a SA-methyltransferase from the pathogen in OXR2-OE plants that could contribute to the phenotype.
\end{abstract}

Keywords: Arabidopsis thaliana; clubroot disease; defense induction; oxidation resistant 2; Plasmodiophora brassicae; PBSMT; salicylic acid

\section{Introduction}

The clubroot disease belongs to the most harmful diseases among brassica crops, including oilseed rape, cabbages, broccoli, cauliflower, etc. and is caused by the obligate biotrophic protist Plasmodiophora brassicae [1]. The symptoms rely on the strong deformation of the roots mediated by plant hormones, including auxins, cytokinins, and brassinosteroids [2-4]. The clubbed roots have a strongly reduced capacity to transport nutrients into the shoot [5,6], thus causing secondary symptoms of wilting and reduced yield [7]. In addition, the pathogen is highly resistant in the soil and can reside there for more than 12 years and is still, after a long time, capable of causing infection with host plants present [8]. The infected roots produce millions of resting spores [9] after the complex life cycle is completed [10]. Moreover, the development of many pathotypes after the selection in fields have been observed worldwide $[9,11-14]$, as well as the modulation of disease by soil microbiota [15]. Therefore, and due to the obligate biotrophic nature of P. brassicae, the disease is difficult to control and relies often on the cultivation of resistant varieties [7,9].

Several experiments have tried to increase the plant defense pathway via salicylic acid (SA), known to be induced after the infection with biotrophic and hemibiotrophic pathogens $[16,17]$, to combat the clubroot since some transcriptome studies indicate the involvement of the SA pathway also during the clubroot disease [18-22]. For example, the comparison between resistant and susceptible brassica cultivars indicated the upregulation of SA-related genes [23]. 
In the case of the clubroot disease, the capacity to reduce disease symptoms by the application of SA seems to be dependent on the specific time point. While a pre-treatment resulted in the control of the disease [24,25], the application of SA seems to depend on a specific time point to result in a reduction of symptoms [26]. Nevertheless, plants that have been treated with high concentrations of SA show an induction of PR genes $[19,20,22,27]$ and enzymes involved in presumable defense reactions, such as peroxidase and chitinase [27,28]. This phenomenon was at least partially attributed to an effector of P. brassicae with homology to plant SABATH-type methyltransferases that can methylate SA in vitro [29]. In addition, it was shown to be secreted into the plant cell by an indirect method [30]. Transgenic plants overexpressing this gene, coined $\mathrm{PbBSMT}$, were more susceptible to the protist [31] and produced more methylated SA, indicating that the enzyme is functioning also in planta [30]. The methylated SA was transported faster to the infected leaves compared to controls, indicating that the role of PbBSMT might be to take away the active SA from the roots to the shoots, at least as shown for Arabidopsis thaliana [29]. Further evidence for the importance of $\mathrm{PbBSMT}$ is its high occurrence as a transcript already during the early stages of infection [29]. Moreover, it was found as one of the major transcripts in a resistant part of the plant compared to controls [22]. The transcript localized within cells that are harboring plasmodia up to the resting spore formation [32]. Interestingly, in the partial resistant interaction of $P$. brassicae with the $A$. thaliana ecotype Bur-0, which had a slight elevation of SA after pathogen infection, an additional treatment of SA resulted in a stronger reduction of clubroot symptoms [18].

Consequently, $A$. thaliana plants that have constitutively elevated SA levels were more resistant to $P$. brassicae infection, whereas mutants in the SA biosynthetic pathway were more susceptible [26,33]. Constitutive high SA levels usually cause dwarfism of the plants, as seen, for example, in the $A$. thaliana mutants $d n d$ and $c p r$ [34-36] (Figure 1). This decrease in weight cannot only be observed after the SA treatments or elevated constitutive SA levels in plants, but also after the treatments with analogs for the SA-induced defense, such as benzothiadiazole (BTH) [37], since the SA and analogs are also in the crossroads between defense and growth [38]. Recently, a gene was identified from $A$. thaliana that encodes a mitochondrial protein with as yet an unknown function $[39,40]$. Overexpression of this OXR2 gene resulted in a phenotype with constitutively activated SA defense response in A. thaliana that caused the plant to be more resistant to Pseudomonas syringae infection [40]. Despite its high SA levels [40], the plant growth was enhanced compared to the wild type (WT) (Figure 1). To the best of our knowledge, this is the first report regarding the fact that a plant was showing high SA levels and at the same time was not compromised in its growth. The oxr 2 mutant plants were actually smaller and showed a higher susceptibility. Therefore, it was assumed that the OXR2 protein somehow regulates the SA-dependent defense mechanisms. As a first mechanism, it was indicated that in OXR2-OE lines the increase of SA resulted in a stronger location of the SA receptor NPR1 [41], in the nucleus [40]. Furthermore, both OXR2 overexpressor lines showed an increased expression in genes for the SA biosynthesis and PR1, a marker for the SA-dependent pathway [40].

In this study, the effect of OXR2 overexpression was investigated on the clubroot development. While in various transcriptome assays the OXR2 gene was not induced, the constitutive overexpression resulted in more tolerant plants to P. brassicae infection, while the mutant was more susceptible. Therefore, the OXR2 protein could be a novel target for independent breeding on resistance proteins. 
A
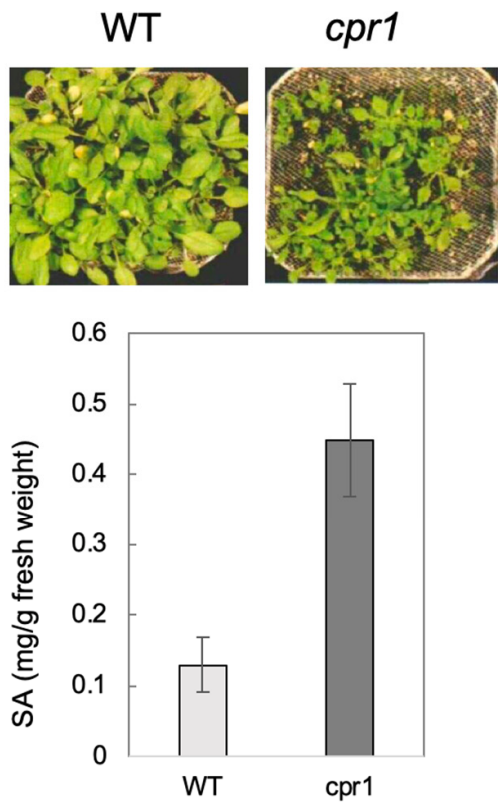

B
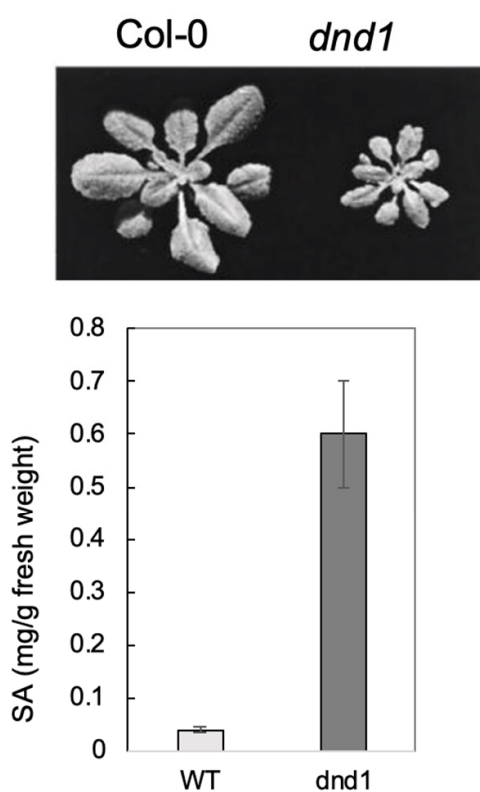

C
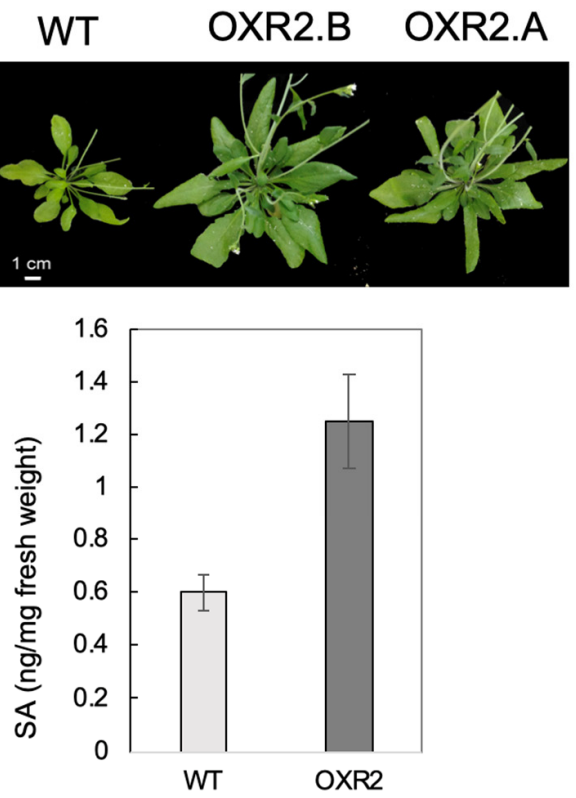

Figure 1. Three different mutants that show constitutively increased SA levels. The comparison with previously published data was made to further illustrate the differences between dwarfed growth phenotypes of plant lines with high SA and the OXR2 overexpressor lines that exhibit an elevated growth from this study. (A) Comparison of WT and cpr1 mutant; pictures are with permission from [34] (copyright 1994, Oxford University Press). (B) Comparison of WT and dnd1 mutant; pictures are with permission from [36] (copyright 2000, National Academy of Sciences, USA). (C) Comparison of WT and constitutive OXR2 overexpressor plants; pictures from R. Mencia, this manuscript. All data panels were redrawn with editorial or author permissions $[34,35,40]$.

\section{Materials and Methods}

\subsection{Plant and Pathogen Materials}

Arabidopsis thaliana (ecotype Columbia, Col-0) was used throughout this study unless otherwise specified. Transgenic plants overexpressing the OXR2 gene (OXR2-OE lines) and homozygous T-DNA mutants (oxr 2 ) were described in $[39,40]$. For P. brassicae, the single spore isolate e3 was used [42]. The original spore isolate was propagated by an infection of Brassica rapa ssp. pekinensis (Chinese cabbage) as described below, and galls were stored at $-20{ }^{\circ} \mathrm{C}$. Resting spores were extracted by homogenizing mature clubroot galls of Chinese cabbage, followed by filtering through gauze $(25 \mu \mathrm{m}$ pore width) and two centrifugation steps $(2500 \times g, 10 \mathrm{~min}$; [43]). Spore solutions resuspended in tap water were stored until use at $-20^{\circ} \mathrm{C}$.

\subsection{Plant Growth and Infection Procedure}

Plants were grown on soil in a greenhouse at $22-24{ }^{\circ} \mathrm{C}$ under long-day conditions (16 h light) at a light intensity of $100 \mu \mathrm{mol} \mathrm{m} \mathrm{m}^{-2} \mathrm{~s}^{-1}$. For $P$. brassicae infection experiments, 14-day-old plants were inoculated with a $2 \mathrm{~mL}$ spore suspension $\left(10^{7}\right.$ spores $\mathrm{mL}^{-1}$ in $50 \mathrm{mM}$ $\mathrm{KH}_{2} \mathrm{PO}_{4}$, pH 5.5) per plant or with a $2 \mathrm{~mL}$ control solution (50 $\left.\mathrm{mM} \mathrm{KH}_{2} \mathrm{PO}_{4}, \mathrm{pH} 5.5\right)$ by slowly pipetting the solution on the soil next to each plant. For each plant line and independent experiment, 30 plants were inoculated of which 20 were used for the phytopathological analyses and 10 randomly selected roots for RNA extraction where appropriate.

For disease rating, plants were removed from the soil and the progression of the clubroot disease was assessed by rating the roots of the infected plants according to reference [44]; see the description below. The resulting time points after inoculation are given as 
days after inoculation (dai) in the respective experimental descriptions (Figure legends and text). The disease index (DI) was calculated according to [44] using the following equation:

$$
\mathrm{DI}=(1 \mathrm{n} 1+2 \mathrm{n} 2+3 \mathrm{n} 3+4 \mathrm{n} 4) \times 100 / 4 \text { Ntotal }
$$

where $\mathrm{n} 1$ to $\mathrm{n} 4$ denotes the number of plants in the indicated disease class and Ntotal is the total number of plants tested. These classes refer to: 0 -no symptoms; 1 -very small clubs on lateral roots, 2-small clubs covering the main root and few lateral roots; 3 -medium to bigger sized clubs including the main roots, plant growth can be impaired; 4 -severe clubs in lateral, main root or rosette, fine roots destroyed, plant roots impaired. Moreover, the shoot index (SI) was quantified by dividing the dry weight (DW) of the infected plants by the control plants DW of the same genotype and time point [43].

\subsection{RNA Isolation and Analysis}

RNA samples of 10 plants per treatment were prepared with the TRIZOL RNA Isolation Reagent (Life Technologies, Carlsbad, CA, USA). Thereafter, $10 \mu \mathrm{g}$ were digested with DNAse I (New England Biolabs, Ipswitch, MA, USA) and the quality of the RNA was inspected on agarose gels. Samples were transcribed to cDNA using $1 \mu \mathrm{g}$ RNA with the Protoscript II FirstStrand cDNA synthesis kit and random primer mix (New England Biolabs, Hitchin, UK). Quantitative real-time PCR (qRT-PCR) was performed on an aliquot of cDNA with specific primers (Table 1) using a qTower 2.2 with the qPCRsoft software (version 3.2, Analytik Jena AG, Jena, Germany). PCRs were carried out in $20 \mu \mathrm{L}$ volume with a 10 pmol primer and $2 \mu \mathrm{L}$ of a 1:10 dilution of cDNA per reaction. The $2 \times$ qPCRBIO SyGreen Mix (PCR Biosystems Ltd., London, UK) was used in a two-step PCR. The reaction conditions were $2 \mathrm{~min}$ at $95^{\circ} \mathrm{C}$ followed by 40 cycles with $15 \mathrm{~s}$ at $95^{\circ} \mathrm{C}$ and $30 \mathrm{~s}$ at $60{ }^{\circ} \mathrm{C}$ followed by melt. The PCRs were run in triplicates and repeated three times with an independently cultivated plant material. For gene expression calculation, the $\Delta \Delta C \mathrm{t}$ method [45] was used with AtACTIN8 in most of the experiments as a reference gene and additionally AtYLS8, AtEF2, and PbActin for the analysis of PbBSMT expression. The primers used in this study were already verified in previous studies $[26,29,31,40]$ or according to the MIQE guidelines for qPCR.

Table 1. Primer sequences used for qPCR in this study.

\begin{tabular}{ccc}
\hline Gene Name & $\mathbf{5}^{\prime}$ Sequence & References \\
\hline AtActins & GTATGTTGCCATTCAAGCTGTTCTA & GAGCTTGGTTTTCGAGGTCTCC \\
\hline AtYLS8 & TTACTGTTTCGGTTGTTCTCCATTT & CACTGAATCATGTTCGAAGCAAGT \\
\hline AtEF2 & TACTCTTATGGTATGACGGATTGTG & ATATGAATGATCGGAAGAGAAAAGA \\
\hline AtSID2 & CTTGGCTAGCACAGTTACAGC & S. Auer, this manuscript \\
\hline PbActin & ATGTCCAACTCGGAGCAGTC & ACTGCAGACACCTAATTGAGTC \\
\hline$P b B S M T$ & GACCTTGCAGAACACGGATT & GGACTCGTTGCCGATCAT \\
\hline
\end{tabular}

\subsection{Sequence Alignment and Phylogenetic Tree Analysis}

Brassica TLDc containing proteins were identified using the Arabidopsis family member AtOXR2 as query using the Brassica database (http://brassicadb.cn/\#/, accessed on 17 October 2021) and the Blastp tool [46,47]. Sixty six homologous sequences from B. oleracea (taxid:3712), B. napus (taxid:3708), B. rapa (taxid:3711), B. cretica (taxid:69181), and $B$. carinata (taxid:52824) were used for the analysis. The protein sequence alignment and the phylogenetic tree were built using the Seaview 4.5.0 software and the PhyML-aLRT-SHLIKE algorithm [48] with maximum likelihood tree reconstruction.

\subsection{Transcriptional Expression Analysis Using Publicly Available Datasets and Bioinformatics Online Tools}

For the expression and GO analysis, data from representative publicly available transcriptome datasets were analyzed in Virtual Plant 1.3 (http: / / virtualplant.bio.nyu.edu/ 
cgi-bin/vpweb/, accessed on 10 November 2021) [49]. Venn diagrams were plotted in Interactive Venn (http:/ / www.interactivenn.net/, accessed on 10 November 2011) [50] and the $p$-values were calculated with the exact Fisher test. The cutoff considered for the analysis was $p<0.05$, using the algorithms included in the Virtual Plant 1.3 database, according to Katari et al. (2010) [49].

\subsection{Statistical Analysis}

Data were analyzed by the ordinary one-way ANOVA and the means were compared by Tukey or Fisher's least significant difference (LSD) tests. Statistical analysis was performed using the default parameters of the InfoStat, version 2013 for Windows (http:/ / www.infostat.com.ar/, accessed on 12 November 2021).

\section{Results}

\subsection{OXR2 Overexpressing Arabidopsis Thaliana Plants Are More Resistant to Clubroot}

Recently, we shown that the overexpression of the A. thaliana gene OXR2, encoding a mitochondrial protein, alters a constitutive defense via the SA pathway, but without compromising plant growth [40]. Inoculation of OXR2 overexpressing $A$. thaliana with $P$. brassicae resulted in a decrease of clubroot symptoms, while the fresh weight of the upper plant parts was actually increased (Figure 2). On the contrary and as expected, the oxr 2 mutant plants showed increased susceptibility to $P$. brassicae infection, resulting in less upper plant part fresh weight. The disease incidence as determined by the disease index (DI), the infection rate, and the shoot index all show better performance of the two OXR2 overexpressing lines A and B compared to WT, while the mutants were again more susceptible (Figure 3 and Figure S1). For all assays, the infection rate was 100\% for all lines, but despite this high infection, the performance of the overexpressors was better than the controls (Figure 3 and Figure S1). Data are shown for plants 28 days after inoculation (dai) with P. brassicae.
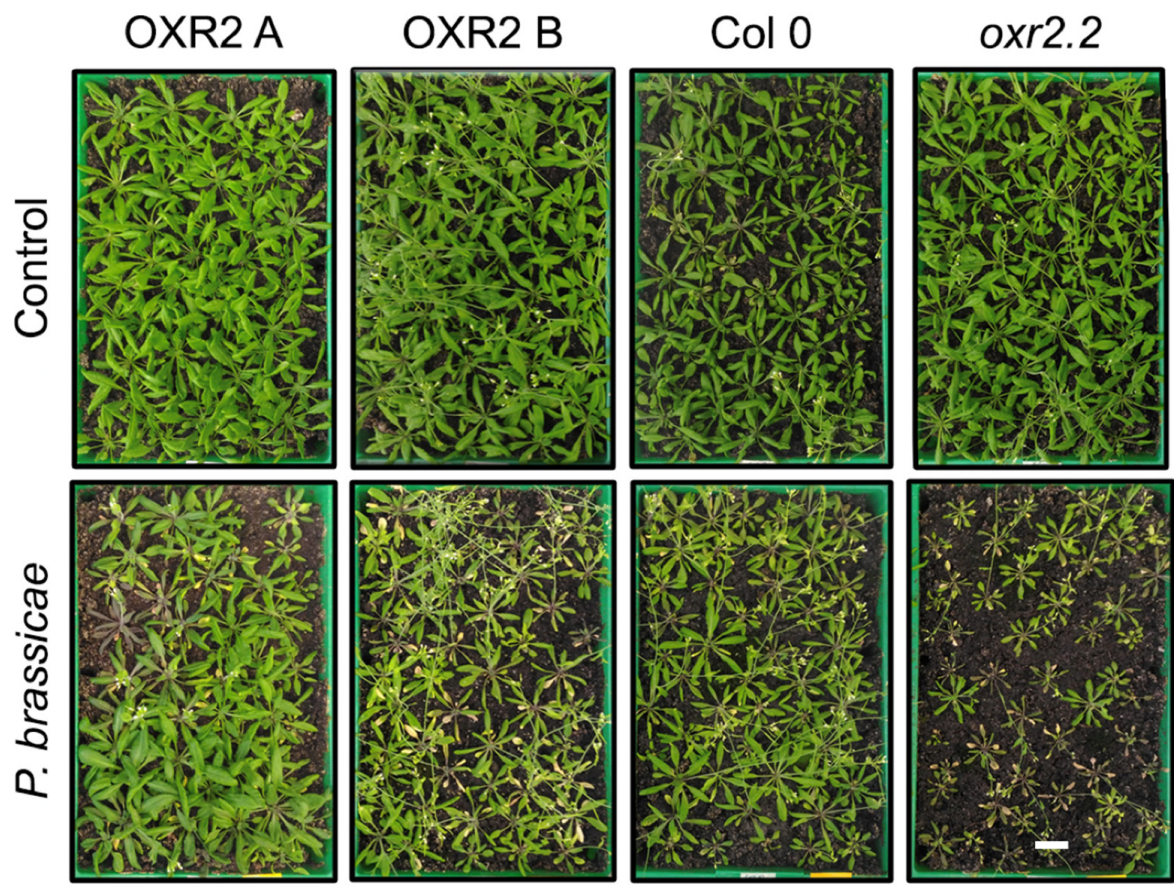

Figure 2. Upper plant parts of representative trays after inoculation of Col-0, oxr2 and two independent OXR2-OE lines (A and B) with $10^{6}$ spores $\mathrm{mL}^{-1}$ of $P$. brassicae (see also Figure $3 \mathrm{C}$, shoot index). The control plants were only inoculated with the buffer that had been used to resuspend the resting spores. The photos were taken 28 dai. The bar is the same size for all panels and represents $2 \mathrm{~cm}$. 
A

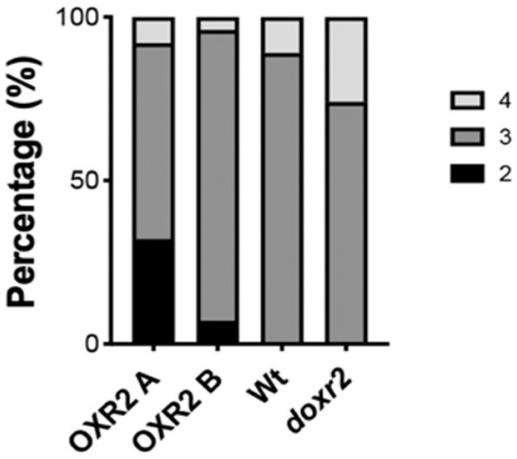

$\mathrm{B}$

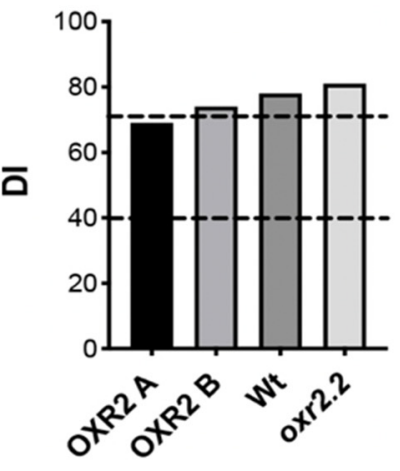

C

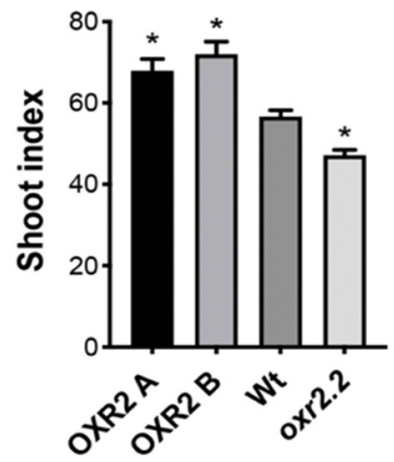

Figure 3. Inoculation of Col-0, oxr2, and two independent OXR2-OE (OXR2 A, OXR2 B) plants with $10^{6}$ spores $\mathrm{mL}^{-1}$ of $P$. brassicae. The controls were inoculated only with the buffer that had been used to resuspend the resting spores of the pathogen (see methods). In each experiment, one tray with 30 plants per condition in total was investigated. The data were evaluated 28 dai as a measure for disease severity. (A) The disease index (DI) (B), the percentage of plants in individual disease classes, and $(\mathrm{C})$ the shoot index (shoot dry weight of infected vs. control plants) are given. Disease class $2=$ small galls, class $3=$ large galls, but the roots are still present, $4=$ large galls, no roots are present. Results are expressed as mean $\pm \mathrm{SD}(n=20)$. Asterisks indicate significant differences between genotypes at $\left.p<0.01{ }^{*}\right)$ (ANOVA, LSD Fisher test).

In general, a low disease index and high shoot index stands for more tolerant plants. The disease index (DI) gives an estimate of the severity of the disease. Plants with a DI of $\geq 90$ were termed as highly susceptible, a DI between 90 and 70 as susceptible, between 40 and 70 indicates moderately resistant/tolerant plants, and a DI of $\leq 40$ stands for resistant populations. The experiments were carried out as three completely independent sets of plants grown at two different seasons and therefore, were presented in this way (Figure 3 and Figure S1). No clear significant differences could be found between the WT and overexpressor lines or mutant plants for the DI (Figure 3, upper panel). However, when the data are expressed as a percent in individual disease classes, the better performance of the overexpressor lines becomes obvious (Figure 3, middle panel). Only the OXR2-OE 
lines showed the plants in the disease class 2 indicating small galls, while WT and oxr2 had only galls in class 3 and 4 . The apparent phenotype (Figure 2) can also be measured and displayed as the infected shoot weight vs. control. This shoot index is a measure for the performance of the green plant parts and overall health of the plants. In both independent experiments, the two independent OXR2-OE lines performed significantly better than WT and the oxr2 mutant, the latter had a lower shoot index (Figure 3, lower panel). A higher shoot index is the indicator of better plant growth despite the disease progression. Therefore, it was determined at a later time point in the disease development (28 dai).

Another measure for the performance of the plants is the amount of pathogen that was able to develop in the inoculated roots. To determine the amount of $P$. brassicae present in the galls, a quantitative real-time qRT-PCR was carried out using the expression of PbActin vs. AtActin as reference genes (Figure 4). The lower number of actin transcripts from $P$. brassicae indicates that there is less pathogen in the tissue compared to the host plant transcripts. The PbActin:AtActin relation was much lower in the OXR2-OE lines compared to WT and oxr 2 mutants, indicating that the reduction in disease severity is accompanied by a reduction of the pathogen load. The time point of analysis was 20 dai, which is earlier than the time points of disease evaluation. However, during that earlier time point, a more active plasmodia of $P$. brassicae should be present. Therefore, the evaluation of an earlier time point will represent what is happening in the more active tissue (Figure 4).

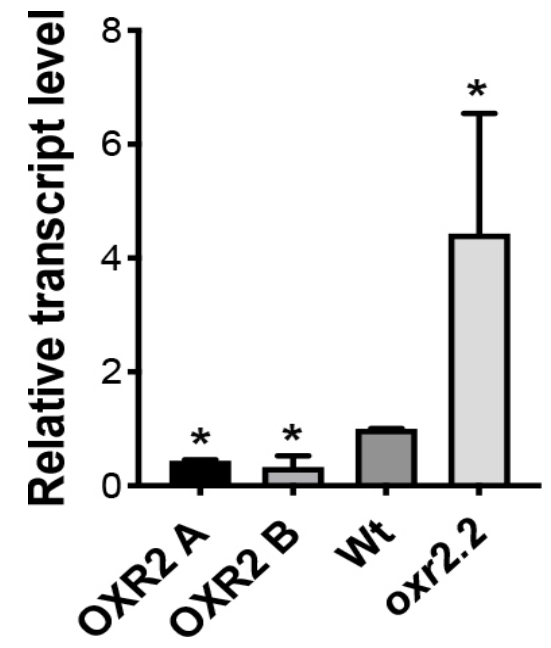

Figure 4. Relative transcript levels of PbActin vs. AtActin determined by qPCR at 20 dai in OXR2-OE lines $A$ and $\mathrm{B}, \mathrm{WT}$, and oxr 2 plants. Low relative transcript levels denote that a small amount of pathogen is present relative to the host cells. Asterisks indicate significant differences of tree biological replicates of each genotype at $p<0.01\left(^{*}\right)$ (ANOVA, LSD Fisher test).

\subsection{Some Molecular Characteristics of OXR2-OE Plants}

AtOXR2 overexpressor lines contain, even without infection, high levels of SA ([40], Figure 1). Since the effect of OXR2 overexpression is very striking on the reduction of the clubroot disease, it was investigated whether the SA biosynthesis from the plant might be altered or whether an alteration of transcripts from $P$. brassicae were found. The expression of SID2, a gene encoding a protein in the SA biosynthetic pathway, was monitored for overexpressors, mutants, and WT (Figure 5). The expression of AtSID2 relative to AtActin as expressed in clubroots vs. controls was not significantly altered (Figure 5) at the same time point where P. brassicae was reduced in the host cells (Figure 4). This corroborates the previous finding that the initial constitutive upregulation is responsible for the more tolerant phenotype and not a later upregulation of the SA pathway. 


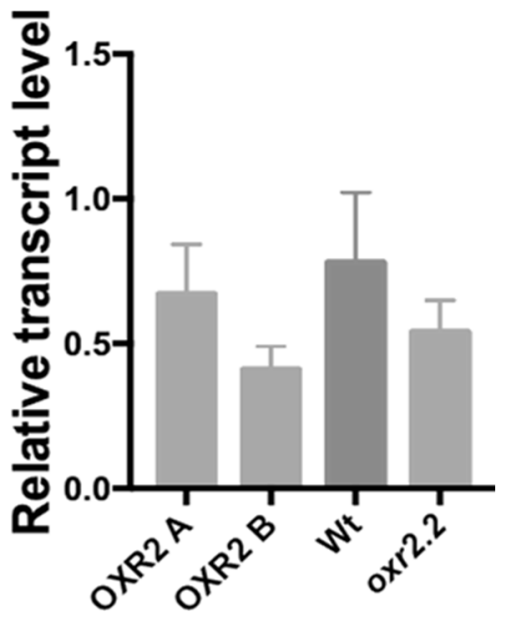

Figure 5. The relative transcript level of AtSID2, encoding an enzyme from the SA biosynthetic pathway as a marker for its possible regulation. Relative transcription determined based on AtActin and by comparing the infected roots to the control roots 20 dai. Results are expressed as mean $\pm S D$ $(n=3)$.

A gene from $P$. brassicae that encodes a SABATH-type methyltransferase had been previously characterized and suggested to play a role in the downregulation of the SAdependent defense pathway in host plants [21,29]. The methyltransferase has high affinity for SA. Therefore, using qPCR, we tested how its expression was regulated in OXR2-OE and oxr 2 mutants compared to WT galls. The expression of PbBSMT was calculated based on a reference gene PbActin. The transcription of $\mathrm{PbBSMT}$ was consistently downregulated in OXR2-OE plants and upregulated compared to WT in the oxr2 mutant line (Figure 6). The same results were found when the PbBSMT transcript was normalized to three different plant reference genes (Figure S2).

A

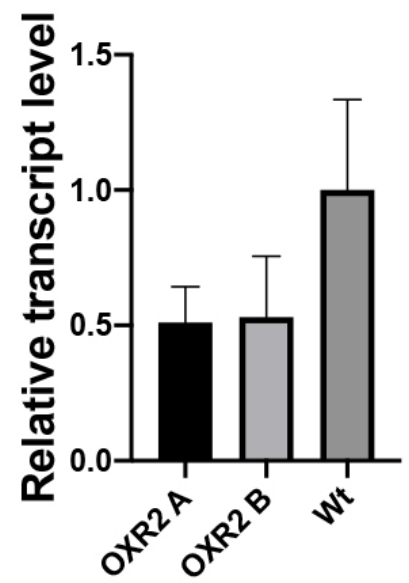

B

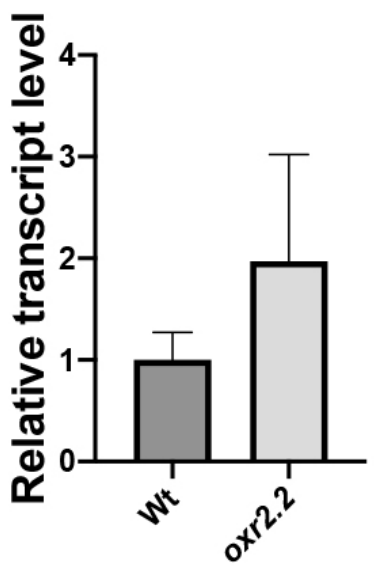

Figure 6. PbBSMT expression normalized to PbActin in roots 20 dai in (A) OXR2 A and B overexpressor lines and (B) mutant oxr2 plants compared to wild type. Results are expressed as mean $\pm \mathrm{SD}$.

\subsection{Homologs of the AtOXR2 Protein Are Also Present in Other Brassica Species}

The clubroot disease is a problem for economically important Brassica crop species, including B. napus, B. rapa, and B. oleracea, which are also severely affected by the clubroot. In a recent analysis where AtOXR2 was first published, a homolog of OXR2 was present in a plethora of plants, but only one from a Brassica species (B. rapa) was included [39]. 
To determine if the OXR2 member is present in this species, we have carried out a search using AtOXR2 as a query in the public genome Brassica database (http:/ /brassicadb. $\mathrm{cn} / \# /$, accessed on 17 October 2021) for B. oleracea (taxid:3712), B. napus (taxid:3708), B. rapa (taxid:3711), B. cretica (taxid:69181), and B. carinata (taxid:52824) using the BlastP tool at NCBI. Sixty six potential AtOXR2 homologs with a significant E-value were found in all of the analyzed species. The highest number of genes was found in B. napus followed by B. rapa and B. cretica (Figure 7A). The three former constitute important economical crops that are known to be highly affected by the clubroot $[6,7,11,14,20]$. As expected, the higher percentage of sequence identity was observed at the C-terminal portion of the protein corresponding to the TLDc family domain (Figure S3). A phylogenetic tree was built using the Seaview 4.5.0 software and the PhyML-aLRTSH-LIKE algorithm with 100 replicates for the bootstrap analysis [48]. There was no clear cluster containing one species, rather the phylogenetic tree contained several clusters where the species from different genera were found in a scattered manner (Figure 7B). A more detailed analysis of OXR protein sequences could help in identifying them for targeted breeding inducing clubroot tolerance in this species.

\subsection{Interaction between the AtOXR2 Pathway and Publicly Available Clubroot Transcriptome Datasets}

Since the effect of OXR2 overexpression is very striking on the reduction of the clubroot disease, we wanted to know whether the available transcriptional data obtained from AtOXR2-OE plants [39] is comparable with the available public datasets (Table 2).

The data are from different time points (hours to weeks), as well as ecotypes (Col-0, Bur-0, and Tsu-0). Therefore, the dataset can be assumed to be representative $[18,24,51,52]$. At least in the partially resistant interaction of Bur- 0 with P. brassicae an indication for the SA pathway was described [18], while the resistant interaction of Tsu-0 with P. brassicae leads to a hypersensitive response [53]. In none of the abovementioned datasets, a differential regulation of AtOXR2 was found. This indicates that the protein OXR2 is normally neither a target for the susceptible nor for a (partially) resistant interaction. Moreover, the different time points covered in these datasets (hours to weeks) exclude the fact that one would miss the expression.

The analysis of GO enrichment terms from opposite genes regulated in AtOXR2-OE plants and susceptible $A$. thaliana (Col-0) after 10 and 23 days after P. brassicae inoculation [50] shows genes coding proteins that are involved in lipid binding, as well as the transport and response to the jasmonic acid stimulus (Table S1A). Agarwal et al. [24] analyzed differentially expressed genes (DEGs) after 4, 7, and 10 days of infection (dai). Genes shared $(p<0.001)$ with AtOXR2 overexpressing plants are implicated in sulfurcompound metabolic processes (Table S1B). DEGs in the experimental design contributed by Jubault et al. [54] and those genes overexpressed in AtOXR2-OE plants are implicated in response to the temperature stimulus and stress (Table S1C). Finally, AtOXR2 plants exhibit a basal lower expression of genes coding for proteins involved in secondary metabolism and anthocyanin synthesis, those that are upregulated after the P. brassicae inoculation (Table S1E) [55]. In terms of total overlap between transcriptomes, there was a strikingly high number of similarly regulated genes, both up and downregulated, between the AtOXR2-OE transcriptome and the transcriptome of the incompatible interaction with the A. thaliana ecotype Tsu-0 [52,53]. Several defense-related genes were present among the genes, but these did not constitute the majority of functions. 
A

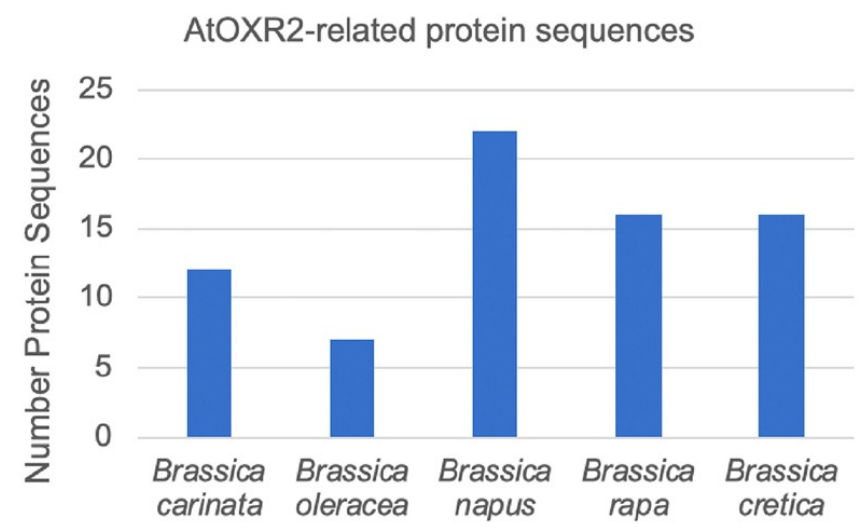

B

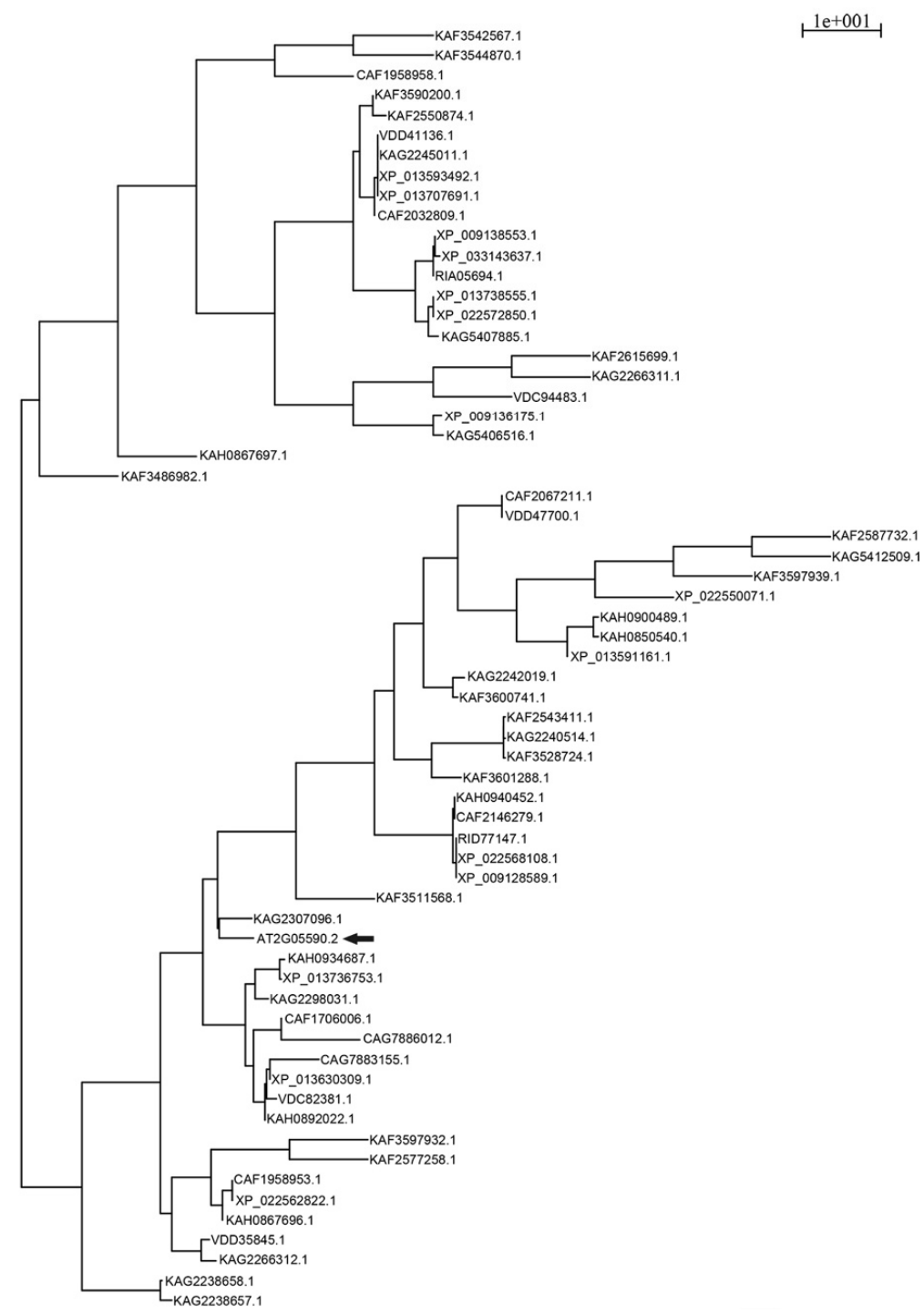

Figure 7. (A) Analysis of the AtOXR2 (AT2G05590) homologs in Brassica species. The number of AtOXR2-related proteins distributed in the different species identified from the Brassica database (http:/ / brassicadb.cn/\#/, accessed on 17 October 2021) and the Blastp tool [46,47]. Sixty six homologous sequences from B. oleracea (taxid:3712), B. napus (taxid:3708), B. rapa (taxid:3711), B. cretica (taxid:69181), and B. carinata (taxid:52824) were used for the analysis. (B) Phylogenetic tree showing the relationship of AtOXR2 to the other Brassica species, obtained using the Seaview 4.5.0 software and the PhyML-aLRT-SH-LIKE algorithm [48] with maximum likelihood tree reconstruction. See Figure S3 for the sequence alignment of proteins used to build this comparison tree. 
Table 2. Analysis of publicly available transcriptomic datasets for the expression of OXR2 in P. brassicae/A. thaliana interactions.

\begin{tabular}{|c|c|c|}
\hline & AtOXR2-OE Downregulated [39] & AtOXR2-OE Upregulated [39] \\
\hline \multicolumn{3}{|c|}{$\begin{array}{l}\text { Siemens et al. [51] } \\
\text { Key outcome: Role of cytokinins } \\
\text { Microarray: } 10,23 \text { dai }^{1}\end{array}$} \\
\hline 10 dai downregulated & n.s. ${ }^{2}$ & $12<0.001$ \\
\hline 23 dai downregulated & n.s. & $18<0.001$ \\
\hline 23 dai upregulated & $12<0.001$ & $12(0.001)$ \\
\hline \multicolumn{3}{|c|}{$\begin{array}{c}\text { Agarwal et al. [24] } \\
\text { Key outcome: Role of defense genes } \\
\text { Microarray: 4, 7, } 10 \text { dai }\end{array}$} \\
\hline 4 dai downregulated & $14<0.001$ & n.s. \\
\hline 10 dai downregulated & $4(0.003)$ & n.s. \\
\hline 4 dai upregulated & n.s. & $23(0.008)$ \\
\hline 7 dai upregulated & $23(0.002)$ & n.s. \\
\hline \multicolumn{3}{|c|}{$\begin{array}{c}\text { Jubault et al. } \\
\text { Key outcome: Ecotype Bur-0 (partially resistant phenotype) }->\text { activation of SA pathway } \\
\text { Microarray: } 24,48 \text { h, } 7 \text { dai }\end{array}$} \\
\hline 1 dai upregulated & n.s. & $12<0.001$ \\
\hline 2 dai upregulated & n.s. & $7<0.001$ \\
\hline 7 dai upregulated & n.s. & $14<0.001$ \\
\hline 7 dai $\mathrm{eH} / \mathrm{e} 2$ downregulated & n.s. & $9<0.001$ \\
\hline e2 specific repression & n.s. & $8<0.001$ \\
\hline \multicolumn{3}{|c|}{$\begin{array}{c}\text { Siemens [52] } \\
\text { Key outcome: Ecotype Tsu-0 (resistant phenotype) that shows HR reactions } \\
\text { Microarray: 10, 14, } 23 \text { dai }\end{array}$} \\
\hline 10 dai downregulated & $54<0.001$ & $59<0.001$ \\
\hline 10 dai upregulated & $89<0.001$ & n.s. \\
\hline 14 dai downregulated & $85<0.001$ & $74<0.001$ \\
\hline 14 dai upregulated & n.s. & $104(0.002)$ \\
\hline \multicolumn{3}{|c|}{$\begin{array}{c}\text { Irani et al. [55] } \\
\text { Key outcome: Role of phenylpropanoid metabolism } \\
\text { RNAseq: } 17,20,24 \text { dai }\end{array}$} \\
\hline $17,20,24$ dai downregulated & n.s. & $6(0.003)$ \\
\hline $17,20,24$ dai upregulated & $16<0.001$ & n.s. \\
\hline
\end{tabular}

${ }^{1}$ dai: Days after inoculation/infection; ${ }^{2}$ n.s.: No significant interaction.

In a recent work, Chen et al. [56] postulated that SnRK1.1 has a biological function in the plant-mediated resistance of $A$. thaliana plants to clubroot disease. The SnRK1.1 activity is inhibited by the $P$. brassicae effector PBZF1, facilitating the infection. To explore a possible connection between the defense pathway mediated by SnRK1.1 and AtOXR2, we analyzed transcriptional data obtained from AtOXR2-OE plants [39] and a list of SnRK1 (=KIN10) target genes previously described [57]. A statistically significant overlap $(p<0.001)$ between the upregulated genes in A. thaliana plants overexpressing AtOXR2 and protoplast transiently overexpressing KIN10 was identified (Figure 8A) (Table S2A). Gene ontology (GO) enrichment analysis of the list of co-regulated genes correspond to those related to respond to the stimulus and stress (Table S2B). Remarkably, relevant genetic markers of the KIN10 pathway [57] are similarly up and downregulated in the AtOXR2-OE plants $(p<0.001)$, as we expected in KIN10-regulated pathways (Figure 8B). From the list, ASN1, SEN5, AXP, MYB75, and JMT are SnrK1.1 gene markers that become mis-regulated in $A$. thaliana plants overexpressing the P. brassicae effector gene PBZF1 [56]. Five of the six genes from Figure $8 \mathrm{~B}$ were also found to be reversely regulated in the transcriptome of mature clubroots [51], i.e., those downregulated were upregulated and those upregulated were repressed (the exception was At3g21500; data not shown). Here, we obtained the same results for clubroots as shown by overexpressing the $P$. brassicae effector gene PBZR1 [56]. Therefore, P. brassicae targets the KIN10 pathway to avoid detection. The 
same pathway could be the target in AtOXR2-OE plants. This assumption needs of course further experimental evidence.

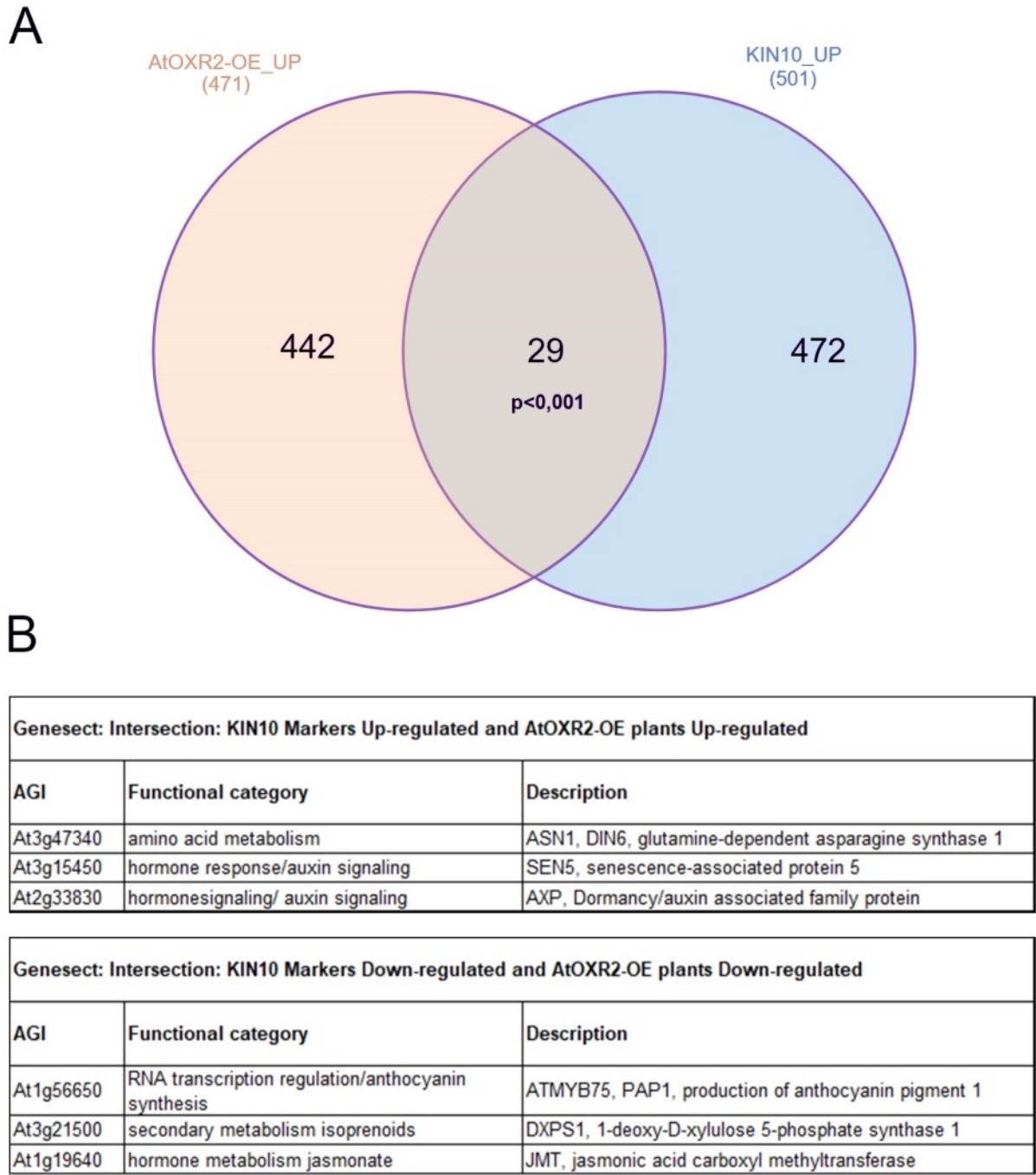

Figure 8. (A) Analysis of the interaction between the AtOXR2-mediated pathway [39] and KIN10 (=SnRF1) regulated genes [57]. The interaction was plotted using the Interactivenn tool (http:/ / www.interactivenn.net/, accessed on 10 November 2021) [50]. See Table S2 for the list of 29 genes statistically shared $(p<0.001)$ by both datasets. (B) List of KIN10 (=SnRF1) gene markers statistically represented as co-regulated genes in AtOXR2-OE plants and protoplast transiently expressing KIN10. Genesect interaction is a bioinformatic tool at the Virtual Plant system database (http:/ / virtualplant. bio.nyu.edu/ 10 November 2021) [49].

\section{Discussion}

Plants with elevated SA levels normally show a reduction in growth, in order that this strategy cannot be used to control the clubroot (Figure 1A,B). Recently, we have shown that the overexpression of the $A$. thaliana gene $O X R 2$, encoding a mitochondrial protein, alters the constitutive defense via the SA pathway, but actually concomitantly increases plant growth [40]. This is ideal for disease control (Figure 1C). The clubroot disease is a challenge to control due to its complex and intracellular life cycle $[1,6,8,10]$. Furthermore, the protist alters the host metabolism and hormone balance [2-5], ultimately leading to reduced growth and the development of upper plant parts [5]. Not many chemical treatment options are available. Therefore, the control in the field often relies on the availability and growth of resistant cultivars [58-60], but is complicated by the evolution of novel, 
more aggressive pathotypes in the field $[9,11,14,60]$. As a result, finding novel targets for breeding is of high economical interest, excluding genes that encode receptor proteins, which are usually quickly overcome by more virulent populations $[9,11,60]$. The existence of a plethora of pathotypes worldwide [61] makes these tasks difficult and therefore, additional targets not involving the classical R-genes are needed. However, pyramiding genes encoding proteins that contribute to tolerance are time consuming, but there are examples for QTLs that accompany clubroot resistance/tolerance [62,63]. The comparison of susceptible and resistant cultivars in terms of their hormone or defense gene profile had been an approach to identify additional factors that are involved in the resistant phenotype [20,22,64]. Apart from the classical resistance gene-receptor interactions that control clubroot disease resistance, the majority of reports point to an involvement of SA in the response $[20,22,23]$. This observation is supported by some biocontrol studies, in which SA-related genes were also upregulated (reviewed in [65]).

The treatment of $A$. thaliana with SA before inoculation resulted in a reduction of a disease index to 20 (control ca 80) [24]. Moreover, this strategy works for Brassica species in the greenhouse [25], but is too complicated for routine procedures in the field. Whether this treatment could be integrated in a sowing procedure has to be evaluated. Furthermore, the increased SA-related gene expression caused a reduction of clubroots, but also in growth [26]. The mutants cpr1 and $d n d 1$ had a reduction in disease incidence of 4.3- and 3-fold, respectively, compared to WT [26]. The SA-dependent defense pathway was also upregulated in a partially resistant interaction with the $A$. thaliana ecotype Bur- 0 and P. brassicae in comparison to Col-0 as a host [18]. The treatment of this partially resistant A. thaliana ecotype after $P$. brassicae inoculation additionally with SA resulted in a further reduction of the disease severity. Consequently, Bur-0 had a disease index of 61 before and 45 after the SA treatment, whereas Col-0 had 85 and 78, respectively [18]. Recently, we have shown that the overexpression of the A. thaliana gene OXR2, encoding a mitochondrial protein, alters the constitutive defense via the SA pathway, and concomitantly increases plant growth $[39,40]$. This is ideal for disease control. In addition, we could show that A. thaliana constitutively overexpressing OXR2 (OXR2-OE) showed an increased resistance to Pseudomonas syringae infection, while mutant oxr 2 was more susceptible [40].

OXR proteins in plants have only recently been discovered to play a role in development and pathogen responses, specifically for $A$. thaliana. The OXR2 protein seems to evolve later and constitutes a plant specific branch [39]. Recently, it was shown that $A$. thaliana plants with altered OXR2 transcript levels were more tolerant to the hemibiotrophic bacterium Pseudomonas syringae [40]. This basal tolerance was dependent on the induction of the NPR1-dependent signaling pathway leading to constitutively induced SA levels [40]. While there are many reports that elevated SA increases pathogen resistance, the plants with constitutively increased SA contents are usually dwarfed (Figure 1) [34-36], in order that they cannot be used as a breeding target. Marker-assisted resistance breeding has been applied for the clubroot [59]. While the overexpression of AtOXR2 led to the higher SA, the growth of the plants was not compromised [40], making OXR2 a promising target to investigate other plant diseases where the SA-dependent defense is upregulated [66].

During the course of clubroot development in A. thaliana, there is evidence for a role of SA. Ecotypes that show partial tolerance to the clubroot, for example, have an increased SA level [18]. Other mutants with increased SA levels showed a drastic reduction of symptoms, albeit at the expense of dwarfism [34-36]. Treating A. thaliana plants with SA before inoculation with $P$. brassicae led to a decrease in symptoms $[24,26]$. One interpretation for the SA-dependent response was found with a putative P. brassicae effector that is capable of methylating the defense hormone [29-31]. Its expression was already detected early during the pathogenesis [29]. Furthermore, its expression was highly upregulated in a susceptible vs. resistant interaction in healthy vs. diseased root parts of a Brassica species [21]. Overexpression resulted in more susceptible plants and higher Me-SA levels [30,31]. In addition, at least in an artificial yeast system, the potential of this effector to be secreted from the intracellular pathogen into the host cell has been demonstrated [30]. The PbBSMT 
transcript was localized in cells harboring developmental stages from plasmodia to resting spore formation [32]. For the first time, these experiments have linked a potential effector of $P$. brassicae to defense suppression.

Moreover, other plant pathogenic organisms secrete effectors that have been connected to the SA response of the respective host plant [67]. This review discussed three possibilities for all plant pathogens to interfere with the SA-dependent host defense: The first strategy is to reduce SA accumulation directly by converting SA into its inactive derivatives. The second strategy is to interrupt SA biosynthesis by targeting the ICS1 pathway. In the third strategy, an interference with SA downstream signaling is observed [68]. P. brassicae seems to exploit at least one of them, namely the interference with the SA levels of the host by secreting a SA-specific methyltransferase [29]. In the overexpressor lines, the amount of PbBSMT transcript was reduced (Figure 6 and Figure S2). Whether this is the direct result of the OXR2 gene overexpression or whether a downstream component is involved in this transcriptional misregulation of $P b B S M T$ is currently unknown. The most prominent example for a microbial effector involved in the SA response of the host plant is a bacterial SA hydroxylase (NahG gene from the soil bacterium Pseudomonas putida) that is also used to genetically modify SA [68]. In addition, NahG transgenic plants were more susceptible to the clubroot disease [26]. Other SA modifying genes were identified in the biotrophic fungus Ustilago maydis, of which one has been shown to be functional [69]. Therefore, U. maydis also employs the strategy to reduce the SA dependent host defense by degrading SA, albeit using a different enzymatic mechanism in comparison to P. brassicae. Additionally, $U$. maydis secretes a functional chorismate mutase that competes with the plant's pathway for SA biosynthesis and thus, also reduces SA levels [67]. In a similar manner, Verticillium dahlia secretes an isochorimatase as an effector into the host, which interferes basically with the same pathway [70]. The strategy is not restricted to the oomycete or fungal pathogens, since a root pathogenic nematode, Meloidogyne incognita, uses the same enzymes, chorismate mutase, to interfere with the plant immunity [71]. Other effectors target various members of the signal transduction chain [67].

While PbBSMT targets the SA pathway, other (putative) P. brassicae effectors have been identified by bioinformatic methods only [72] and possible functions only for a few suggested [73-76]. Among these were a kinase [73], a putative E3 ubiquitin ligase [74], an apoplastic protein able to directly interact with and inhibit cruciferous papain-like cysteine proteases [75], as well as endomembrane-localized effectors that modulate PAMP triggered immunity [76]. Other proteins, for which a function has been implicated, do not seem to fall under the category "effector", e.g., the protease PRO1 that possibly helps in spore germination [77]. The identification of a P. brassicae effector interacting with a kinase [56] from a pathway known to be involved in abiotic and biotic stress interactions $[57,78]$ led us to investigate whether the target pathway in $A$. thaliana could also be a target for the tolerance of AtOXR2-OE plants. Although we have not identified an increase of AtOXR2 transcription during $P$. brassicae infection, according to the data analyzed from previous studies $[24,51,52,54,55]$ (Table 2), the increased levels of SA [39,40] obtained in AtOXR2-OE plants modify the basal defenses and the cellular redox environment, allowing for the plant to be better prepared to avoid the entry of the pathogen and the infection. The comparison of gene expression in the course of different assays with $P$. brassicae infected roots with the transcriptional profile of AtOXR2-OE plants, grown under normal conditions, show a common regulation of genes involved in lipid metabolism, in the synthesis of anthocyanin, in the response to stimuli and stress (Table S1). They are all general responses, characteristic of plants with increased basal defense responses. Moreover, we observed an increase in the expression of KIN10 gene targets (Figure 8A). KIN10 or SnRK1.1 is involved in the trade-off between energy use from growth-associated processes to survival and defense in response to biotic stresses [78,79]. SnRK1.1 confers broad-spectrum disease resistance in wheat, barley, and rice [80]. Recently, it was demonstrated that SnRK1.1 enhances the resistance of Arabidopsis to the clubroot disease and is counteracted by the P. brassicae effector PBZF1, producing a disequilibrium of the expression levels of SnRK1.1-regulated 
genes [56]. Several of these genes are regulated in our OXR2-OE plants, in the same way as in Arabidopsis protoplasts overexpressing KIN10 (Figure 8B). A further experimental analysis must be conducted to decipher the mechanism by which plants are better prepared to deal with the clubroot disease.

The OXR2-OE lines do not show a tremendous reduction of galls tissue, but have an increased biomass that could be of interest to practical applications in the field. Moreover, since the amount of P. brassicae is significantly reduced in these galls, the overall effect on the reduction of disease severity could be a good argument for the field. Therefore, we have analyzed other Brassica species for the occurrence of AtOXR2 homologs, which were found in several brassica crops (Figure 7). In this case, we found homologous proteins with an high level of sequence identity, especially at the level of the carboxy-terminal portion of the proteins. This is where the TLDc domain is located, which is characteristic of the OXR family, in all of the analyzed Brassica species, including those with a commercial value. Therefore, these could be interesting targets for additional breeding in these crops increasing the SA levels together with a better overall growth of leaves, as described for A. thaliana $[39,40]$. Overall, the constitutive SA phenotype of the OXR2-OE lines might contribute to the observed tolerance, rather than an additional increase in SA during the clubroot, since the transcription of SID2 as a marker gene for the SA biosynthetic pathway was not upregulated in the infected roots (Figure 5).

\section{Conclusions}

A. thaliana plants overexpressing a gene encoding the mitochondrial protein OXR2, that have been shown to constitutively express SA defense-related pathways, were more tolerant to the causal agent of the clubroot disease in brassica crops P. brassicae. The function was confirmed in mutant oxr 2 plants, which were more susceptible. In these plants, the putative effector of $P$. brassicae, PbBSMT, was downregulated on the transcript level. PbBSMT is involved in the methylation and concomitantly reduction of SA in the infected roots. Therefore, OXR2 could be able to circumvent the effector action. As a result, the OXR2 protein might be a novel target that needs to be considered in the generation of clubroot tolerant plants, especially since its regulation of the upper plant parts performance is promising. With less pathogen present in the root galls, lower spore numbers are formed that can ultimately be released to the soil. This reduction of pathogen load is important since it can contribute to the clubroot control in the field. The findings from $A$. thaliana might help in elucidating the role of OXR2 for the clubroot disease in many economically important Brassica species.

Supplementary Materials: The following are available online at https: / www.mdpi.com/article/ 10.3390/horticulturae8010009/s1. Figure S1: Data from the individual additional infection experiments after inoculation of WT (Co-0), oxr2, and OXR2-OE plants with $P$. brassicae resting spores; Figure S2: PbBSMT expression normalized to the plant genes AtActin, AtYLS8, and AtE2FB in roots 20 dai in OXR2 $A$ and $B$ overexpressor lines and mutant $0 x r 2$ plants; Figure S3: Multiple sequence alignments for Brassica OXR2 homologs in comparison with Arabidopsis thaliana; Table S1: Genesect interaction and GO analysis between the transcriptomic data of AtOXR2-OE plants (Colombatti et al. [39]) and different clubroot transcriptome data; Table S2: Genesect interaction and GO analysis between the transcriptomic data of AtOXR2-OE plants (Colombatti et al. [39]) and AtKIN10-OE plants $(=S n R K 1)[56]$.

Author Contributions: Conceptualization, J.L.-M., E.W. and R.M.; methodology, R.M. and S.A.; validation, R.M., E.W. and S.A.; writing—original draft preparation, J.L.-M.; writing-review and editing, J.L.-M., R.M., S.A. and E.W. All authors have read and agreed to the published version of the manuscript.

Funding: This research was funded by Centro Universitario Argentino-Alemán-Deutsch-Argentinisches Hochschulzentrum (CUAA-DAHZ) in the frame of a Binational Ph.D. Program, PICT2017-2340 and PICT2019-0310 (E.W.).

Institutional Review Board Statement: Not applicable. 
Informed Consent Statement: Not applicable.

Data Availability Statement: More data supporting this manuscript can be found in the supplement. Additional data files are available upon request from authors. The references to public databases that were used to generate data are given in the manuscript.

Acknowledgments: We thank Freia Benade and Sabine Rößler, Technische Universität Dresden for technical support. We thank Centro Universitario Argentino-Alemán-Deutsch-Argentinisches Hochschulzentrum, for supporting Regina Mencia in the frame of the Binational Ph.D. Program.

Conflicts of Interest: The authors declare no conflict of interest.

\section{References}

1. Dixon, G.R. Plasmodiophora brassicae (Clubroot): A Plant Pathogen that Alters Host Growth and Productivity. J. Plant Growth Regul. 2009, 28, 193. [CrossRef]

2. Jahn, L.; Mucha, S.; Bergmann, S.; Horn, C.; Staswick, P.; Steffens, B.; Siemens, J.; Ludwig-Müller, J. The Clubroot Pathogen (Plasmodiophora brassicae) Influences Auxin Signaling to Regulate Auxin Homeostasis in Arabidopsis. Plants 2013, 2, 726-749. [CrossRef] [PubMed]

3. Robin, A.H.K.; Hossain, M.R.; Kim, H.-T.; Nou, I.-S.; Park, J.-I. Role of Cytokinins in Clubroot Disease Development. Plant Breed. Biotechnol. 2019, 7, 73-82. [CrossRef]

4. Schuller, A.; Kehr, J.; Ludwig-Müller, J. Laser Microdissection Coupled to Transcriptional Profiling of Arabidopsis Roots Inoculated by Plasmodiophora brassicae Indicates a Role for Brassinosteroids in Clubroot Formation. Plant Cell Physiol. 2013, 55, 392-411. [CrossRef] [PubMed]

5. Malinowski, R.; Truman, W.; Blicharz, S. Genius Architect or Clever Thief-How Plasmodiophora brassicae Reprograms Host Development to Establish a Pathogen-Oriented Physiological Sink. Mol. Plant-Microbe Interact. 2019, 32, 1259-1266. [CrossRef]

6. Zhang, W.; Wang, S.; Yu, F.; Tang, J.; Yu, L.; Wang, H.; Li, J. Genome-Wide Identification and Expression Profiling of Sugar Transporter Protein (STP) Family Genes in Cabbage (Brassica oleracea var. capitata L.) Reveals their Involvement in Clubroot Disease Responses. Genes 2019, 10, 71. [CrossRef]

7. Dixon, G.R. The Occurrence and Economic Impact of Plasmodiophora brassicae and Clubroot Disease. J. Plant Growth Regul. 2009, 28, 194-202. [CrossRef]

8. Dixon, G.R. Plasmodiophora brassicae in its Environment. J. Plant Growth Regul. 2009, 28, 212-228. [CrossRef]

9. Hwang, S.F.; Ahmed, H.U.; Zhou, Q.; Rashid, A.; Strelkov, S.E.; Gossen, B.D.; Peng, G.; Turnbull, G.D. Effect of susceptible and resistant canola plants on Plasmodiophora brassicae resting spore populations in the soil. Plant Pathol. 2013, 62, 404-412. [CrossRef]

10. Liu, L.; Qin, L.; Zhou, Z.; Hendriks, W.G.H.M.; Liu, S.; Wei, Y. Refining the Life Cycle of Plasmodiophora brassicae. Phytopathology 2020, 110, 1704-1712. [CrossRef]

11. Fredua-Agyeman, R.; Hwang, S.-F.; Strelkov, S.E.; Zhou, Q.; Feindel, D. Assessment of resistance to 'new' virulent populations of Plasmodiophora brassicae reveals potential loss of clubroot resistance genes from donor parent Brassica rapa L. ssp. rapifera (ECD 04) during doubled haploid production. Plant Pathol. 2017, 67, 892-901. [CrossRef]

12. Sedaghatkish, A.; Gossen, B.D.; Yu, F.; Torkamaneh, D.; McDonald, M.R. Whole-genome DNA similarity and population structure of Plasmodiophora brassicae strains from Canada. BMC Genom. 2019, 20, 744-814. [CrossRef] [PubMed]

13. Pang, W.; Liang, Y.; Zhan, Z.; Li, X.; Piao, Z. Development of a Sinitic Clubroot Differential Set for the Pathotype Classification of Plasmodiophora brassicae. Front. Plant Sci. 2020, 11, 568771. [CrossRef] [PubMed]

14. Zamani-Noor, N. Variation in pathotypes and virulence of Plasmodiophora brassicae populations in Germany. Plant Pathol. 2017, 66, 316-324. [CrossRef]

15. Daval, S.; Gazengel, K.; Belcour, A.; Linglin, J.; Sarniguet, A.; Manzanares-Dauleux, M.J.; Mougel, C. Soil microbiota influences clubroot disease by modulating Plasmodiophora brassicae and Brassica napus transcriptomes. Microbial Biotechnol. 2020, 13, 1648-1672. [CrossRef]

16. Hayat, S.; Irfan, M.; Wani, A.S.; Alyemeni, M.N.; Ahmad, A. Salicylic acids: Local, systemic or inter-systemic regulators? Plant Sign. Behav. 2012, 7, 93-102. [CrossRef]

17. Loake, G.; Grant, M. Salicylic acid in plant defence-The players and protagonists. Curr. Opin. Plant Biol. 2007, 10, 466-472. [CrossRef] [PubMed]

18. Lemarié, S.; Robert-Seilaniantz, A.; Lariagon, C.; Lemoine, J.; Marnet, N.; Jubault, M.; Manzanares-Dauleux, M.J.; Gravot, A. Both the jasmonic acid and the salicylic acid pathways contribute to resistance to the biotrophic clubroot agent Plasmodiophora brassicae in Arabidopsis. Plant Cell Physiol. 2015, 56, 2158-2168.

19. Manoharan, R.K.; Shanmugam, A.; Hwang, I.; Park, J.-I.; Nou, I.-S. Expression of salicylic acid-related genes in Brassica oleracea var. capitata during Plasmodiophora brassicae infection. Genome 2016, 59, 379-391. [CrossRef] [PubMed]

20. Prerostova, S.; Dobrev, P.I.; Konradyova, V.; Knirsch, V.; Gaudinova, A.; Kramna, B.; Kazda, J.; Ludwig-Müller, J.; Vankova, R. Hormonal Responses to Plasmodiophora brassicae Infection in Brassica napus Cultivars Differing in Their Pathogen Resistance. Int. J. Mol. Sci. 2018, 19, 4024. [CrossRef] 
21. Ciaghi, S.; Schwelm, A.; Neuhauser, S. Transcriptomic response in symptomless roots of clubroot infected kohlrabi (Brassica oleracea var. gongylodes) mirrors resistant plants. BMC Plant Biol. 2019, 19, 1-14. [CrossRef]

22. Galindo-González, L.; Manolii, V.; Hwang, S.-F.; Strelkov, S.E. Response of Brassica napus to Plasmodiophora brassicae Involves Salicylic Acid-Mediated Immunity: An RNA-Seq-Based Study. Front. Plant Sci. 2020, 11, 1025. [CrossRef]

23. Zhou, Q.; Galindo-González, L.; Manolii, V.; Hwang, S.-F.; Strelkov, S. Comparative Transcriptome Analysis of Rutabaga (Brassica napus) Cultivars Indicates Activation of Salicylic Acid and Ethylene-Mediated Defenses in Response to Plasmodiophora brassicae. Int. J. Mol. Sci. 2020, 21, 8381. [CrossRef] [PubMed]

24. Agarwal, A.; Kaul, V.; Faggian, R.; Rookes, J.E.; Ludwig-Müller, J.; Cahill, D.M. Analysis of global host gene expression during the primary phase of the Arabidopsis thaliana-Plasmodiophora brassicae interaction. Funct. Plant Biol. 2011, 38, 462-478. [CrossRef] [PubMed]

25. Lovelock, D.A.; Donald, C.E.; Conlan, X.A.; Cahill, D.M. Salicylic acid suppression of clubroot in broccoli (Brassica oleracea var italica) caused by the obligate biotroph Plasmodiophora brassicae. Australas. Plant Pathol. 2013, 42, 141-153. [CrossRef]

26. Lovelock, D.A.; Sola, I.; Marschollek, S.; Donald, C.E.; Rusak, G.; van Pée, K.H.; Ludwig-Müller, J.; Cahill, D.M. Analysis of salicylic acid-dependent pathways in Arabidopsis thaliana following infection with Plasmodiophora brassicae and the influence of salicylic acid on disease. Mol. Plant Pathol. 2016, 7, 1237-1251. [CrossRef] [PubMed]

27. Chen, J.; Piao, Y.; Liu, Y.; Li, X.; Piao, Z. Genome-wide identification and expression analysis of chitinase gene family in Brassica rapa reveals its role in clubroot resistance. Plant Sci. 2018, 270, 257-267. [CrossRef] [PubMed]

28. Ludwig-Müller, J.; Thermann, P.; Pieper, K.; Hilgenberg, W. Peroxidase and chitinase isoenzyme activities during root infection of Chinese cabbage with Plasmodiophora brassicae. Physiol. Plant. 1994, 90, 661-670. [CrossRef]

29. Ludwig-Müller, J.; Jülke, S.; Geiß, K.; Richter, F.; Mithöfer, A.; Šola, I.; Rusak, G.; Keenan, S.; Bulman, S. A novel methyltransferase from the intracellular pathogen Plasmodiophora brassicae methylates salicylic acid. Mol. Plant Pathol. 2014, 16, 349-364. [CrossRef] [PubMed]

30. Djavaheri, M.; Ma, L.; Klessig, D.F.; Mithöfer, A.; Gropp, G.; Borhan, H. Mimicking the Host Regulation of Salicylic Acid: A Virulence Strategy by the Clubroot Pathogen Plasmodiophora brassicae. Mol. Plant-Microbe Interact. 2019, 32, 296-305. [CrossRef]

31. Bulman, S.; Richter, F.; Marschollek, S.; Benade, F.; Jülke, S.; Ludwig-Müller, J. Arabidopsis thaliana expressing PbBSMT, a gene encoding a SABATH-type methyltransferase from the plant pathogenic protist Plasmodiophora brassicae, show leaf chlorosis and altered host susceptibility. Plant Biol. 2019, 21, 120-130. [CrossRef]

32. Badstöber, J.; Gachon, C.M.M.; Ludwig-Müller, J.; Sandbichler, A.M.; Neuhauser, S. Demystifying biotrophs: FISHing for mRNAs to decipher plant and algal pathogen-host interaction at the single cell level. Sci. Rep. 2020, 10, 14269. [CrossRef] [PubMed]

33. Wildermuth, M.C.; Dewdney, J.; Wu, G.; Ausubel, F.M. Isochorismate synthase is required to synthesize salicylic acid for plant defence. Nature 2001, 414, 562-565. [CrossRef] [PubMed]

34. Bowling, S.A.; Guo, A.; Cao, H.; Gordon, S.; Klessig, D.; Dong, X. A mutation in Arabidopsis that leads to constitutive expression of systemic acquired resistance. Plant Cell 1994, 6, 1845-1857. [PubMed]

35. Yu, I.-C.; Parker, J.; Bent, A.F. Gene-for-gene disease resistance without the hypersensitive response in Arabidopsis $d n d 1$ mutant. Proc. Natl. Acad. Sci. USA 1998, 95, 7819-7824. [CrossRef] [PubMed]

36. Clough, S.J.; Fengler, K.A.; Yu, I.; Lippok, B.; Smith, R.K., Jr.; Bent, A.F. The Arabidopis sdnd1 “defense, no death" gene encodes a mutated cyclic nucleotide-gated ion channel. Proc. Natl. Acad. Sci. USA 2000, 97, 9323-9328. [CrossRef]

37. Canet, J.V.; Dobón, A.; Ibáñez, F.; Perales, L.; Tornero, P. Resistance and biomass in Arabidopsis: A new model for Salicylic Acid perception. Plant Biotechnol. J. 2010, 8, 126-141. [CrossRef]

38. Rivas-San Vicente, M.; Plasencia, J. Salicylic acid beyond defence: Its role in plant growth and development. J. Exp. Bot. 2011, 62, 3321-3338. [CrossRef]

39. Colombatti, F.; Mencia, R.; Garcia, L.; Mansilla, N.; Alemano, S.; Andrade, A.M.; Gonzalez, D.H.; Welchen, E. The mitochondrial oxidation resistance protein AtOXR2 increases plant biomass and tolerance to oxidative stress. J. Exp. Bot. 2019, 70, 3177-3195. [CrossRef]

40. Mencia, R.; Céccoli, G.; Fabro, G.; Torti, P.; Colombatti, F.; Ludwig-Müller, J.; Alvarez, M.E.; Welchen, E. OXR2 Increases Plant Defense against a Hemibiotrophic Pathogen via the Salicylic Acid Pathway. Plant Physiol. 2020, 184, 1112-1127. [CrossRef] [PubMed]

41. Mhamdi, A. NPR1 Has Everything under Control. Plant Physiol. 2019, 181, 6-7. [CrossRef]

42. Fähling, M.; Graf, H.; Siemens, J. Pathotype Separation of Plasmodiophora brassicae by the Host Plant. J. Phytopathol. 2003, 151, 425-430. [CrossRef]

43. Siemens, J.; Nagel, M.; Ludwig-Müller, J.; Sacristán, M.D. The interaction of Plasmodiophora brassicae and Arabidopsis thaliana: Parameters for disease quantification and screening of mutant lines. J. Phytopathol. 2002, 150, 592-605. [CrossRef]

44. Klewer, A.; Luerßen, H.; Graf, H.; Siemens, J. RFLP markers to characterize Plasmodiophora brassicae single-spore-isolates with different virulence patterns. J. Phytopathol. 2001, 149, 1-7. [CrossRef]

45. Livak, K.J.; Schmittgen, T.D. Analysis of relative gene expression data using real-time quantitative PCR and the $2^{(-\Delta \Delta C t)}$ method. Methods 2001, 25, 402-408. [CrossRef]

46. Altschul, S.F.; Gish, W.; Miller, W.; Myers, E.W.; Lipman, D.J. Basic local alignment search tool. J. Mol. Biol. 1990, 215, 403-410. [CrossRef]

47. Gish, W.; States, D.J. Identification of protein coding regions by database similarity search. Nat. Genet. 1993, 3, 266-272. [CrossRef] 
48. Gouy, M.; Guindon, S.; Gascuel, O. SeaView Version 4: A Multiplatform Graphical User Interface for Sequence Alignment and Phylogenetic Tree Building. Mol. Biol. Evol. 2009, 27, 221-224. [CrossRef] [PubMed]

49. Katari, M.; Nowicki, S.D.; Aceituno, F.F.; Nero, D.; Kelfer, J.; Thompson, L.P.; Cabello, J.M.; Davidson, R.S.; Goldberg, A.P.; Shasha, D.E.; et al. VirtualPlant: A Software Platform to Support Systems Biology Research. Plant Physiol. 2009, 152, 500-515. [CrossRef] [PubMed]

50. Heberle, H.; Meirelles, G.V.; Da Silva, F.R.; Telles, G.P.; Minghim, R. InteractiVenn: A web-based tool for the analysis of sets through Venn diagrams. BMC Bioinform. 2015, 16, 169. [CrossRef] [PubMed]

51. Siemens, J.; Keller, I.; Sarx, J.; Kunz, S.; Schuller, A.; Nagel, W.; Schmülling, T.; Parniske, M.; Ludwig-Müller, J. Transcriptome Analysis of Arabidopsis Clubroots Indicate a Key Role for Cytokinins in Disease Development. Mol. Plant-Microbe Interact. 2006, 19, 480-494. [CrossRef] [PubMed]

52. NASC's International Affymetrix Service. Available online: http://arabidopsis.info/affy/link_to_iplant.html (accessed on 9 October 2021).

53. Kobelt, P.; Siemens, J.; Sacristán, M.D. Histological Characterisation of the Incompatible Interaction between Arabidopsis Thaliana and the Obligate Biotrophic Pathogen Plasmodiophora brassicae. Mycol. Res. 2000, 104, 220-225. [CrossRef]

54. Jubault, M.; Lariagon, C.; Taconnat, L.; Renou, J.-P.; Gravot, A.; Delourme, R.; Manzanares-Dauleux, M.J. Partial resistance to clubroot in Arabidopsis is based on changes in the host primary metabolism and targeted cell division and expansion capacity. Funct. Integr. Genom. 2013, 13, 191-205. [CrossRef] [PubMed]

55. Irani, S.; Trost, B.; Waldner, M.; Nayidu, N.; Tu, J.; Kusalik, A.J.; Todd, C.D.; Wei, Y.; Bonham-Smith, P.C. Transcriptome analysis of response to Plasmodiophora brassicae infection in the Arabidopsis shoot and root. BMC Genom. 2018, 19, 1-19. [CrossRef]

56. Chen, W.; Li, Y.; Yan, R.; Ren, L.; Liu, F.; Zeng, L.; Sun, S.; Yang, H.; Chen, K.; Xu, L.; et al. SnRK1.1-mediated resistance of Arabidopsis thaliana to clubroot disease is inhibited by the novel Plasmodiophora brassicae effector PBZF1. Mol. Plant Pathol. 2021, 22, 1057-1069. [CrossRef]

57. Baena-González, E.; Rolland, F.; Thevelein, J.; Sheen, J. A central integrator of transcription networks in plant stress and energy signalling. Nature 2007, 448, 938-942. [CrossRef]

58. Liu, Y.; Xu, A.; Liang, F.; Yao, X.; Wang, Y.; Liu, X.; Zhang, Y.; Dalelhan, J.; Zhang, B.; Qin, M.; et al. Screening of clubroot-resistant varieties and transfer of clubroot resistance genes to Brassica napus using distant hybridization. Breed. Sci. 2018, 68, 258-267. [CrossRef]

59. Mehraj, H.; Akter, A.; Miyaji, N.; Miyazaki, J.; Shea, D.J.; Fujimoto, R.; Doullah, A.-U. Genetics of Clubroot and Fusarium Wilt Disease Resistance in Brassica Vegetables: The Application of Marker Assisted Breeding for Disease Resistance. Plants 2020, 9, 726. [CrossRef]

60. Dakouri, A.; Lamara, M.; Karim, M.; Wang, J.; Chen, Q.; Gossen, B.D.; Strelkov, S.E.; Hwang, S.-F.; Peng, G.; Yu, F. Identification of resistance loci against new pathotypes of Plasmodiophora brassicae in Brassica napus based on genome-wide association mapping Sci. Rep. 2021, 11, 6599. [CrossRef]

61. Schwelm, A.; Ludwig-Müller, J. Molecular pathotyping of Plasmodiophora brassicae-Genomes, marker genes and obstacles. Pathogens 2021, 10, 259. [CrossRef]

62. Fredua-Agyeman, R.; Jiang, J.; Hwang, S.-F.; Strelkov, S.E. QTL Mapping and Inheritance of Clubroot Resistance Genes Derived From Brassica rapa subsp. rapifera (ECD 02) Reveals Resistance Loci and Distorted Segregation Ratios in Two F2 Populations of Different Crosses. Front. Plant Sci. 2020, 11, 899. [CrossRef]

63. Wagner, G.; Laperche, A.; Lariagon, C.; Marnet, N.; Renault, D.; Guitton, Y.; Bouchereau, A.; Delourme, R.; Manzanares-Dauleux, M.J.; Gravot, A. Resolution of quantitative resistance to clubroot into QTL-specific metabolic modules. J. Exp. Bot. 2019, 70, 5375-5390. [CrossRef]

64. Zamani-Noor, N.; Hornbacher, J.; Comel, C.; Papenbrock, J. Variation of Glucosinolate Contents in Clubroot-Resistant and Susceptible Brassica napus Cultivars in Response to Virulence of Plasmodiophora brassicae. Pathogens 2021, 10, 563. [CrossRef] [PubMed]

65. Ludwig-Müller, J. Belowground defence strategies against clubroot (Plasmodiophora brassicae). In Belowground Defence Strategies in Plants; Series: Signaling and communication in plants; Vos, C., Kamal, K., Eds.; Springer: Berlin/Heidelberg, Germany, 2016; pp. 195-219.

66. Yang, L.; Li, B.; Zheng, X.-Y.; Li, J.; Yang, M.; Dong, X.; He, G.; An, C.; Deng, X.W. Salicylic acid biosynthesis is enhanced and contributes to increased biotrophic pathogen resistance in Arabidopsis hybrids. Nat. Commun. 2015, 6, 7309. [CrossRef] [PubMed]

67. Qi, G.; Chen, J.; Chang, M.; Chen, H.; Hall, K.; Korin, J.; Liu, F.; Wang, D.; Fu, Z.Q. Pandemonium BreaksOut: Disruption of salicylic acid-mediated defense by plant pathogens. Mol. Plant. 2018, 11, 1427-1439. [CrossRef] [PubMed]

68. Gaffney, T.; Friedrich, L.; Vernooij, B.; Negrotto, D.; Nye, G.; Uknes, S.; Ward, E.; Kessmann, H.; Ryals, J. Requirement of Salicylic Acid for the Induction of Systemic Acquired Resistance. Science 1993, 261, 754-756. [CrossRef]

69. Rabe, F.; Ajami-Rashidi, Z.; Doehlemann, G.; Kahmann, R.; Djamei, A. Degradation of the plant defence hormone salicylic acid by the biotrophic fungus Ustilago maydis. Mol. Microbiol. 2013, 89, 179-188. [CrossRef] [PubMed]

70. Liu, T.; Song, T.; Zhang, X.; Yuan, H.; Su, L.; Li, W.; Xu, J.; Liu, S.; Chen, L.; Chen, T.; et al. Unconventionally secreted effectors of two filamentous pathogens target plant salicylate biosynthesis. Nat. Commun. 2014, 5, 4686. [CrossRef] [PubMed] 
71. Wang, X.; Xue, B.; Dai, J.; Qin, X.; Liu, L.; Chi, Y.; Jones, J.T.; Li, H. A novel Meloidogyne incognita chorismate mutase effector suppresses plant immunity by manipulating the salicylic acid pathway and functions mainly during the early stages of nematode parasitism. Plant Pathol. 2018, 67, 1436-1448. [CrossRef]

72. Pérez-López, E.; Waldner, M.; Hossain, M.; Kusalik, A.J.; Wei, Y.; Bonham-Smith, P.C.; Todd, C.D. Identification of Plasmodiophora brassicae effectors-A challenging goal. Virulence 2018, 9, 1344-1353. [CrossRef]

73. Pérez-López, E.; Hossain, M.; Tu, J.; Waldner, M.; Todd, C.D.; Kusalik, A.J.; Wei, Y.; Bonham-Smith, P.C. Transcriptome Analysis Identifies Plasmodiophora brassicae Secondary Infection Effector Candidates. J. Eukaryot. Microbiol. 2020, 67, 337-351. [CrossRef] [PubMed]

74. Yu, F.; Wang, S.; Zhang, W.; Tang, J.; Wang, H.; Yu, L.; Zhang, X.; Fei, Z.; Li, J. Genome-wide identification of genes encoding putative secreted E3 ubiquitin ligases and functional characterization of PbRING1 in the biotrophic protist Plasmodiophora brassicae. Curr. Genet. 2019, 65, 1355-1365. [CrossRef] [PubMed]

75. Pérez-López, E.; Hossain, M.M.; Wei, Y.; Todd, C.D.; Bonham-Smith, P.C. A clubroot pathogen effector targets cruciferous cysteine proteases to suppress plant immunity. Virulence 2021, 12, 2327-2340. [CrossRef] [PubMed]

76. Hossain, M.; Pérez-López, E.; Todd, C.D.; Wei, Y.; Bonham-Smith, P.C. Endomembrane-Targeting Plasmodiophora brassicae Effectors Modulate PAMP Triggered Immune Responses in Plants. Front. Microbiol. 2021, 12, 651279. [CrossRef]

77. Feng, J.; Hwang, R.; Hwang, S.-F.; Strelkov, S.E.; Gossen, B.D.; Zhou, Q.-X.; Peng, G. Molecular characterization of a serine protease Pro1 from Plasmodiophora brassicae that stimulates resting spore germination. Mol. Plant Pathol. 2010, 11, 503-512. [CrossRef]

78. Hulsmans, S.; Rodriguez, M.S.; De Coninck, B.; Rolland, F. The SnRK1 Energy Sensor in Plant Biotic Interactions. Trends Plant Sci. 2016, 21, 648-661. [CrossRef]

79. Margalha, L.; Confraria, A.; Baena-González, E. SnRK1 and TOR: Modulating growth-defense trade-offs in plant stress responses. J. Exp. Bot. 2019, 70, 2261-2274. [CrossRef]

80. Filipe, O.; De Vleesschauwer, D.; Haeck, A.; Demeestere, K.; Höfte, M. The energy sensor OsSnRK1a confers broad-spectrum disease resistance in rice. Sci. Rep. 2018, 8, 3864. [CrossRef] 